\title{
GESTÃO DA QUALIDADE NA CADEIA DE SUPRIMENTOS
}

\section{QUALITY MANAGEMENT IN THE SUPPLY CHAIN}

Cláudia Fabiana Gohr

Professora Adjunta do Departamento de Engenharia de Produção, Universidade Federal da Paraíba (UFPB)

João Pessoa, PB, Brasil

E-mail: claudiagohr@ct.ufpb.br

Cinthia de Azevêdo Faustino

Engenheira de Produção e Mestranda do Programa de Pós-Graduação em Engenharia de Produção da UFPB João Pessoa, PB, Brasil

E-mail: cinthiafaustino@gmail.com

\section{RESUMO}

A busca por uma posição competitiva tem fortalecido os relacionamentos na cadeia de suprimentos a fim de agregar valor, gerando produtos de qualidade. Nesse contexto, esta pesquisa pretende analisar a gestão da qualidade na cadeia de suprimentos de uma indústria calçadista do Estado da Paraíba. Foram identificados dois segmentos de gestão da qualidade relacionados à cadeia de suprimentos: práticas internas e interação com fornecedores. Para a realização do estudo empírico foi utilizada o estudo de caso múltiplo, aplicado na empresa focal e em um fornecedor. Os instrumentos de coleta de dados foram entrevistas, observações e análise documental. A análise qualitativa permitiu identificar a forma como cada uma das empresas atua em relação à gestão interna da qualidade, apontando possibilidades de melhorias. Na interação entre as empresas verificouse que os fornecedores participam ativamente da melhoria da qualidade da empresa focal, mas não existem relacionamentos de parceria consolidados

Palavras-chave: Cadeia de Suprimentos. Gestão da Qualidade. Indústria Calçadista. Práticas Internas de Qualidade. Interação de Qualidade com Fornecedores.

\section{ABSTRACT}

The search for a competitive position has strengthened the relationships in the supply chain in order to add value, generating quality products. This research aims to analyze the quality management in the supply chain of a footwear industry of the State of Paraiba. Were identified two segments of supply chain quality management: internal quality practices and quality interaction with suppliers. We adopted the multiple case study method, applied in a focal firm and a first level supplier. We used interviews and observations. The qualitative analysis allowed to identify how each company operates in relation to the internal quality management, pointing out possibilities for improvement. In the quality interaction between the company with suppliers, it was possible verify that the supplier investigated participate actively in improving the quality in the focal firm, but there are not consolidated partnership relationships between them.

Keywords Supply Chain. Quality Management. Footwear Industry. Internal Quality Practices. Quality Interaction with Suppliers.

Data de aprovação: 15 de julho de 2017.

Data de submissão: 17 de setembro de 2015 


\section{INTRODUÇÃO}

O fenômeno da globalização tem provocado diversos efeitos nos mais variados setores econômicos. Sofyalığlu e Kartal (2012) asseguram que à medida que as atividades de produção e comercialização são internacionalizadas, as empresas têm a capacidade de desenvolver um produto em um país, produzi-lo em um diferente e ainda vendê-lo em outros.

Dessa forma, cada vez mais as empresas têm buscado a difícil missão de alcançar um lugar de destaque no ambiente competitivo globalizado. A variedade de produtos oferecidos nos mais diversos setores é imensa, com ampla possibilidade de compra e venda de itens de qualquer lugar do mundo em pequenos intervalos de tempo. A internet tem contribuído bastante para tornar a competição ainda mais acirrada. Paladini (2009) cita que é a concorrência que dá origem, motivação e razão para a produção da qualidade.

Foster Jr. (2008) afirma que a gestão da qualidade (quality management - QM) segue por duas vertentes: visão interna (foco no processo) e visão externa (foco no cliente). Para Kaynak e Hartley (2008) e Fernandes et al.(2017), é preciso que as empresas também integrem seus processos com os fornecedores para que possam melhorar o desempenho de qualidade. Os autores defendem que as empresas não devem mais focar em práticas internas isoladas. Para se manterem competitivas, elas devem olhar para além de seus processos internos e dos seus interesses particulares, agindo de forma colaborativa (KAYNAK; HARTLEY, 2008). Por isso, a fim de "unir forças", as organizações têm formado os arranjos empresariais como, por exemplo, a cadeia de suprimentos (supply chain - SC).

Nesse sentido, a cadeia de suprimentos aparece como uma saída para que as empresas sobrevivam às exigências do mercado, compartilhando interesses que tragam benefícios conjuntos. A gestão da cadeia de suprimentos (supply chain management - SCM) envolve muitos desafios como, por exemplo, o desenvolvimento de confiança e colaboração entre os parceiros e a identificação de melhores práticas que possam facilitar os processos, o alinhamento e a integração da cadeia.

Zu e Kaynak (2012) afirmam que é necessário que as empresas, em uma cadeia, estabeleçam relações de cooperação com os fornecedores no que diz respeito à gestão da qualidade e melhorias. Nesse sentido, surgem estudos que associam a gestão da qualidade à gestão da cadeia de suprimentos, considerando os principais fatores que devem ser explorados pelos membros da cadeia para alcançarem vantagens competitivas. Dessa forma, Robinson e Malhotra (2005) verificam que o desenvolvimento de pesquisas em gestão da qualidade na cadeia de suprimentos (supply chain quality management - SCQM) está em fase inicial, o que demonstra a possibilidade de desenvolver trabalhos sobre esta temática.

Diante do exposto, este artigo tem como principal objetivo analisar a gestão da qualidade no contexto da cadeia de suprimentos de uma indústria calçadista (empresa focal) do estado da Paraíba. Para isso, inicialmente será preciso analisar as práticas de gestão da qualidade adotadas internamente pela empresa focal e por uma de suas principais fornecedoras de primeira camada (empresa responsável pela produção de laminado, uma matéria-prima crítica e de alto valor agregado ao produto final). Em seguida a análise se estenderá para a interação da qualidade entre as duas empresas. 
O desenvolvimento desta pesquisa tem importante relevância por se tratar de uma temática recente que, segundo Jraisat e Sawalha (2013), ainda não possui um completo entendimento, necessitando de novas investigações. Fernandes et al. (2017) também afirmam que muitas pesquisas sobre o tema têm sido conduzidas de forma separada e apenas poucos trabalham integram as duas perspectivas.

Analisando a literatura da área constatou-se que a maioria das pesquisas possui um caráter empírico (ZHONG, et al., 2016; ZENG; PHAN; MATSUI, 2013; JRAISAT; SAWALHA, 2013; LIN; KUEI; CHAI, 2013; ZAGHA, 2009; KAYNAK; HARTLEY, 2008; ROBINSON; MALHOTRA, 2005; LIN et al., 2005), fazendo com o que o desenvolvimento desta pesquisa também contribua para a literatura empírica sobre o tema. Além disso, a realização do trabalho também se justifica pelo fato de ser aplicado em um setor no qual, de acordo com as pesquisas encontradas, ainda não recebeu contribuição nesse tema.

Para a empresa focal o desenvolvimento deste trabalho é relevante pois pode fornecer uma análise de sua própria forma de executar a gestão da qualidade, verificando se há alinhamento com a forma de gerir a qualidade utilizada pelo seu fornecedor de primeira camada. Em ambos os casos, poder-se-á identificar possibilidades de melhorias que geralmente passam despercebidas diante da rotina de trabalho. Além disso, será possível verificar se a forma como a empresa focal lida com seus fornecedores, em relação aos quesitos de qualidade averiguados, tem possibilitado o alcance de vantagens competitivas.

O trabalho está dividido em cinco seções. A primeira, já descrita, envolveu os elementos introdutórios. Na seção dois é desenvolvido o referencial teórico, com foco na apresentação das pesquisas mais recentes em gestão da qualidade na cadeia de suprimentos. Posteriormente, são descritos os procedimentos metodológicos utilizados para realizar a revisão da literatura e os aspectos norteadores para o desenvolvimento do estudo empírico. Na seção quatro o estudo empírico é apresentado e analisado. Por fim, na quinta e última seção são apresentadas as conclusões, com as contribuições do trabalho e as possibilidades de desenvolvimento de novas pesquisas.

\section{GESTÃO DA QUALIDADE NA CADEIA DE SUPRIMENTOS}

Robinson e Malhotra (2005) afirmam que a gestão da qualidade tradicional dá ênfase no controle e na melhoria dos processos internos, integrando os diversos setores da empresa, como marketing, compras e fabricação. Paladini (2009) defende que quem avalia a qualidade é o consumidor; para atendê-lo, a gestão da qualidade deve envolver todas as áreas, setores e pessoas da empresa de forma permanente. Dessa forma, Paladini (2004) considera que a gestão da qualidade envolve toda a empresa, desenvolvendo-se ao longo do tempo e de maneira contínua, num processo evolutivamente progressivo.

Robinson e Malhotra (2005) afirmam que as empresas começaram a perceber que além da necessidade de implantar a melhoria contínua da qualidade e satisfazer as exigências de seus clientes imediatos, também era necessário competir em mercados globalizados, o que ressaltou a importância da gestão da cadeia de suprimentos, na qual as empresas podem combinar iniciativas estratégicas para atingir a excelência operacional. Para os autores, tanto as empresas quanto os consultores e acadêmicos têm tentado integrar a gestão da cadeia de suprimentos em seus processos de negócios a fim de obter vantagens competitivas. 
Segundo Zeng, Phan e Matsui (2013), a concorrência e a globalização fizeram a gestão da cadeia de suprimentos se tornar uma forma das empresas responderem de maneira rápida, correta e lucrativa às demandas do mercado. Pires (2004) cita algumas características e tendências que vêm ocorrendo na prática em relação às SCM, como: redução do número de fornecedores, gestão colaborativa, outsourcing, in plan representatives, early supplier involvement (ESI), governança e parcerias. Nesse sentido, Zagha (2009) afirma que a SCM está relacionada à coordenação de atividades e processos não apenas dentro do contexto de uma organização isolada, mas sim de todas as empresas que compõem a cadeia de suprimentos. Dessa forma, a autora considera que há benefícios que podem ser obtidos na gestão estratégica de toda a cadeia de suprimentos.

A qualidade tem se tornado uma dimensão significativa e tem tomado um papel fundamental no contexto da SCM (ZENG; PHAN; MATSUI, 2013; PIRES, 2004). Zu e Kaynak (2012) afirmam que as empresas têm encontrado dificuldade em controlar a qualidade dos materiais fornecidos devido à dependência cada vez maior das redes de fornecedores na produção e entrega dos produtos e serviços.

A definição de gestão da qualidade na cadeia de suprimentos envolve três dimensões: práticas de gestão da qualidade interna, interação da qualidade com fornecedores (à montante da cadeia) e interação da qualidade com clientes (à jusante da cadeia), o que a torna um conceito multidimensional (ZENG; PHAN; MATSUI, 2013). Para os autores, é necessário que os membros da cadeia implementem a gestão da qualidade interna e individualmente. A partir disso, as empresas devem olhar para além de sua organização interna e poderão verificar os benefícios de agir de forma colaborativa e integrada entre os seus parceiros, de modo que cada membro possa contribuir positivamente para o sucesso da gestão da qualidade na cadeia.

Zu e Kaynak (2012) consideram que é inevitável que uma empresa esteja exposta a eventos imprevisíveis quando obtém mercadorias e serviços de fornecedores, devido ao processo natural de aquisição, entrega e uso. Assim, para Kaynak e Hartley (2008), os fornecedores desempenham um papel primordial à medida que assseguram que os materiais que oferecem estejam livres de defeitos. Nesse sentido, a qualidade do produto final é garantida a partir da qualidade das entradas, ou seja, das matérias-primas que foram utilizadas (ZU; KAYNAK, 2012).

Considerando que as empresas têm percebido a necessidade de alinhar suas práticas de gestão da qualidade com as práticas de seus parceiros, a literatura mostra que a integração dos conceitos de gestão da qualidade e gestão da cadeia de suprimentos tem se tornado um campo favorável e emergente de pesquisa, especialmente no elo montante da cadeia. Das leituras efetuadas para a construção deste estudo, doze trabalhos sobre SCQM foram destacados, com suas principais características apresentadas no Quadro 1. Esses trabalhos serão brevemente descritos, permitindo conhecer o que a literatura em SCQM tem examinado e quais as formas de análise utilizadas, o que permitirá direcionar o desenvolvimento desta pesquisa. 
Quadro 1 - Características das pesquisas em SCQM

\begin{tabular}{|c|c|c|c|}
\hline Autor(es) & Tipo de Estudo & Método & Setores/Empresas \\
\hline $\begin{array}{c}\text { Fernandes et al. } \\
(2017)\end{array}$ & Teórico & - & - \\
\hline $\begin{array}{c}\text { Zhong, et al } \\
(2016)\end{array}$ & Empírico & Survey & Indústria de turismo na China \\
\hline $\begin{array}{l}\text { Zeng, Phan e } \\
\text { Matsui (2013) }\end{array}$ & Empírico & Survey & $\begin{array}{c}\text { Indústrias de máquinas, } \\
\text { eletroeletrônicos e automóveis em } \\
\text { duzentas e trinta e oito plantas de } \\
\text { oito países (Estados Unidos, } \\
\text { Japão, Itália, Suécia, Áustria, } \\
\text { Coréia, Alemanha } \\
\text { e Finlândia) }\end{array}$ \\
\hline $\begin{array}{c}\text { Jraisat e } \\
\text { Sawalha (2013) }\end{array}$ & Empírico & Estudo de caso & $\begin{array}{l}\text { Cinco empresas da cadeia de } \\
\text { frutas frescas e vegetais na } \\
\text { Jordânia }\end{array}$ \\
\hline $\begin{array}{l}\text { Lin, Kuei e Chai } \\
\qquad(2013)\end{array}$ & Empírico & Survey & $\begin{array}{c}\text { Dezessete empresas fabricantes } \\
\text { de projetos e equipamentos em } \\
\text { Taiwan }\end{array}$ \\
\hline $\begin{array}{c}\text { Zu e Kaynak } \\
(2012)\end{array}$ & Teórico & - & 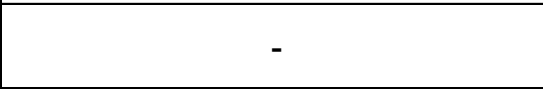 \\
\hline Foster Jr. (2008) & Teórico & - & - \\
\hline $\begin{array}{l}\text { Kaynak e Hartley } \\
(2008)\end{array}$ & Empírico & Survey & $\begin{array}{c}\text { Empresas de manufatura e serviço } \\
\text { dos EUA que utilizam práticas de } \\
\text { gestão da qualidade }\end{array}$ \\
\hline $\begin{array}{c}\text { Robinson e } \\
\text { Malhotra (2005) }\end{array}$ & Empírico & Estudo de caso & $\begin{array}{l}\text { Uma indústria de peças de } \\
\text { automóveis dos EUA }\end{array}$ \\
\hline Lin et al. (2005) & Empírico & Modelagem & $\begin{array}{c}\text { Cento e três empresas de } \\
\text { serviços, incluindo frete, } \\
\text { transporte, vendas por atacado, } \\
\text { comércio e empresas de logística, } \\
\text { localizadas em Taiwan }\end{array}$ \\
\hline $\begin{array}{c}\text { Carmignami } \\
(2009)\end{array}$ & Teórico & - & - \\
\hline Zagha (2009) & Empírico & Estudo de caso & $\begin{array}{l}\text { Duas montadoras de motores para } \\
\text { automóveis e nove fornecedores, } \\
\text { todos localizados no estado de } \\
\text { São Paulo, Brasil }\end{array}$ \\
\hline
\end{tabular}

Fonte: Elaborado pelos autores.

Kaynak e Hartley (2008) identificaram oito práticas de gestão da qualidade na revisão da literatura efetuada por eles: liderança da gestão, treinamentos, $\mathrm{RH}$, foco no cliente, dados de qualidade e emissão de relatórios, gestão da qualidade do fornecedor, design de produto/serviço e gestão de processos. Já para Robinson e Malhotra (2005), as pesquisas em gestão da qualidade no contexto da cadeia de suprimentos podem ser categorizadas da seguinte forma: atividades de comunicação e parceria; integração e gestão de processos; gestão e liderança; estratégia; melhores práticas. 
No trabalho de Lin et al. (2005) os autores identificaram na literatura os fatores críticos da SCQM. Esses fatores são: práticas de gestão da qualidade - liderança da gestão, treinamento, design de produtos e serviços, gestão da qualidade do fornecedor, gestão de processos, comunicação de dados de qualidade, relações com os empregados, relações com os clientes, aprendizagem de referência; participação de fornecedores - participação dos fornecedores no design dos produtos e na melhoria contínua; seleção de fornecedores - seleção orientada para a qualidade e seleção orientada para o custo. Em seu trabalho, Zu e Kaynak (2012) examinaram duas abordagens que as empresas podem utilizar para gerenciar a qualidade do fornecedor, uma abordagem baseada em resultados e a outra em comportamentos.

Já para Zeng, Phan e Matsui (2013) existem três componentes da gestão da qualidade em cadeias de suprimentos: as práticas internas de gestão da qualidade, a interação da qualidade com fornecedores (lado montante da cadeia) e a interação da qualidade com clientes (lado jusante da cadeia). Considerando essas três dimensões, os autores verificaram e agruparam as características associadas a cada uma delas: (i) práticas internas de gestão da qualidade (liderança da gestão de topo, planejamento estratégico, qualidade da informação, gestão de processos, gestão da força de trabalho, processo de design do produto); (ii) interação da qualidade com fornecedores (relação de logo prazo, envolvimento do fornecedor em desenvolvimento de produto e melhoria da qualidade, foco de qualidade na seleção de fornecedores ao invés de centrar-se em preço, seleção e certificação de fornecedores); e, (iii) interação da qualidade com os clientes (reuniões frequentes com os clientes, visitas dos clientes às fábricas, encorajamento de feedback dos clientes sobre a qualidade, envolvimento do cliente no projeto de produto e utilização das necessidades dos clientes nas pesquisas).

Jraisat e Sawalha (2013) identificaram treze fatores do controle de qualidade que estão relacionados à cadeia de suprimentos: compromisso, comunicação, qualidade do produto, qualidade de informações, continuidade, satisfação, liderança, treinamento, fatores ambientais, formulação de políticas, protocolo de qualidade, relacionamento pessoal e apoio financeiro. Lin, Kuei e Chai (2013) identificaram em suas pesquisas fatores chaves para o alto desempenho da gestão da qualidade em cadeias de suprimentos, a saber: comunicação e parceria, liderança, estratégias, práticas de qualidade, gestão de processos, seleção de fornecedores, participação dos fornecedores, foco no cliente e no mercado, informações e análises, gestão e desenvolvimento de recursos humanos.

Por meio de uma cuidadosa revisão bibliográfica, Foster Jr. (2008) identificou os principais temas comuns no estudo de gestão da qualidade em cadeias de suprimentos, destacando os seguintes: foco no cliente, práticas de qualidade, relações com fornecedores, práticas de liderança e recursos humanos, resultados de negócios e segurança.

Já a pesquisa desenvolvida por Zagha (2009) foi dividida em três análises, com os seguintes pontos averiguados em cada uma delas: (i) análise da gestão da qualidade interna - normas da qualidade, política da qualidade, controle da qualidade de matéria-prima, controle da qualidade de processo, controle da qualidade de produto, suporte para melhoria, avaliação do cliente e participação na resolução de problemas; (ii) análise da estrutura da cadeia de suprimentos - principais clientes, total de fornecedores, política de suprimentos, fornecimento exclusivo, origem do capital, porte, capacidade tecnológica, localização, dentre outras características dos fornecedores; e, (iii) análise das relações entre as empresas no interior da cadeia de suprimentos - seleção de fornecedores, avaliação de fornecedores, programas de desenvolvimento de 
fornecedores, poder de negociação da empresa com os fornecedores, relações com outros níveis da cadeia de suprimentos (além de clientes e fornecedores imediatos).

Em seu trabalho, Carmignami (2009) verificou que a norma ISO 9001 é uma certificação direcionada à qualidade no interior das empresas e que ainda não foi definida uma norma para sistemas de gestão da qualidade no contexto da cadeia de suprimentos. Considerando que o objeto de integração da cadeia é focado nos processos ao invés da abordagem centrada no produto, o autor propôs uma norma sistêmica, com conceitos da ISO 9001 redefinidos a fim de serem aplicados à realidade das características da cadeia de suprimentos.

Zhong et al. (2016) investigaram o relacionamento entre práticas de: (i) gestão da qualidade (liderança; benchmarking; foco no cliente; gestão de processos; melhoria contínua; comprometimento dos recursos humanos e aprendizagem; cooperação interna e externa; e, capacidade e segurança dos fornecedores); (ii) gestão da cadeia de suprimentos (integração e coordenação com os parceiros da cadeia; trabalhar com os fornecedores; envolvimento com os parceiros para ter vantagem em função de suas capacidades e conhecimento; compartilhamento de informações, etc.); (iii) qualidade da cadeia de suprimentos (qualidade dos produtos, confiabilidade e flexibilidade da cadeia); e, (iv) desempenho de um empreendimento hoteleiro localizado na China (considerando as seguintes variáveis: financeiro, moral dos empregados e desempenho de clientes).

Por fim, Fernandes et al. (2017) desenvolveram uma base teórica para integrar a gestão da qualidade e a gestão da cadeia de suprimentos. Para tanto, os autores verificaram que algumas práticas comuns podem exercer um impacto positivo nas quatro perspectivas do balanced scorecard, são elas: liderança, planejamento e gestão estratégica, comprometimento e envolvimento com stakeholders, informação, melhoria contínua e inovação.

No Quadro 2 estão apresentadas as práticas de gestão da qualidade relacionadas à cadeia de suprimentos que foram citadas nas pesquisas investigadas ora apresentadas. Essas práticas foram agrupadas nos três componentes citados por Zeng, Phan e Matsui (2013): práticas internas, integração com fornecedores e interação com clientes.

De acordo com o exposto, pode-se afirmar que os estudos sobre gestão da qualidade em cadeias de suprimentos vêm apresentando bastante semelhança nas abordagens que são adotadas. Na maioria dos trabalhos os autores agrupam características de SC e QM, formulam hipóteses e avaliam a correlação entre os fatores examinados. A revisão teórica levou a conhecer e agrupar os critérios relevantes adotados em suas análises. As práticas que irão compor o estudo empírico são formadas pelos elementos que estão apresentados no Quadro 2, com exceção da interação com os clientes. 
Quadro 2 - Práticas de gestão da qualidade relacionadas à cadeia de suprimentos

\begin{tabular}{|c|c|c|}
\hline \multirow{6}{*}{ 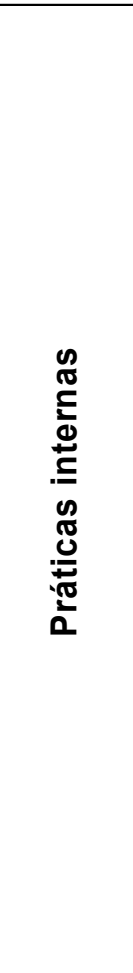 } & Liderança da gestão & $\begin{array}{l}\text { Lin et al. (2005), Kaynak e Hartley (2008), Zeng, } \\
\text { Phan e Matsui (2013), Robinson e Malhotra } \\
\text { (2005), Zhong et al. (2016), Fernandes et al. } \\
\text { (2017) }\end{array}$ \\
\hline & $\begin{array}{l}\text { Gestão de recursos } \\
\text { humanos }\end{array}$ & $\begin{array}{l}\text { Lin et al. (2005), Kaynak e Hartley (2008), Zeng, } \\
\text { Phan e Matsui (2013), Robinson e Malhotra } \\
\text { (2005), Lin, Kuei e Chai (2013), Foster Jr. (2008), } \\
\text { Zagha (2009) }\end{array}$ \\
\hline & Treinamento & $\begin{array}{l}\text { Lin et al. (2005), Kaynak e Hartley (2008), Jraisat } \\
\text { e Sawalha (2013), Robinson e Malhotra (2005), } \\
\text { Zeng, Phan e Matsui (2013), Zhong et al. (2016) }\end{array}$ \\
\hline & Design de produtos & $\begin{array}{l}\text { Lin et al. (2005), Kaynak e Hartley (2008), Zeng, } \\
\text { Phan e Matsui (2013) }\end{array}$ \\
\hline & Gestão de processos & $\begin{array}{l}\text { Lin et al. (2005), Kaynak e Hartley (2008), Zeng } \\
\text { Phan e Matsui (2013), Robinson e Malhotra } \\
\text { (2005) Zagha (2009) Lin, Kuei e Chai (2013) }\end{array}$ \\
\hline & Dados de qualidade & $\begin{array}{l}\text { Lin et al. (2005), Kaynak e Hartley (2008), Zeng, } \\
\text { Phan e Matsui (2013), Jraisat e Sawalha (2013) } \\
\text { Lin, Kuei e Chai (2013) }\end{array}$ \\
\hline \multirow{4}{*}{ 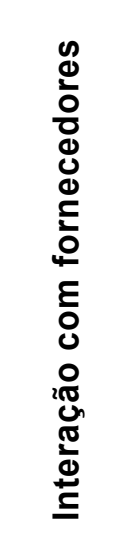 } & $\begin{array}{l}\text { Participação dos } \\
\text { fornecedores no design } \\
\text { dos produtos }\end{array}$ & $\begin{array}{l}\text { Lin et al. (2005), Zeng, Phan e Matsui (2013) } \\
\text { Lin, Kuei e Chai (2013), Kaynak e Hartley (2008) }\end{array}$ \\
\hline & $\begin{array}{l}\text { Participação dos } \\
\text { fornecedores na melhoria } \\
\text { contínua }\end{array}$ & $\begin{array}{l}\text { Lin et al. (2005), Zeng, Phan e Matsui (2013) } \\
\text { Lin, Kuei e Chai (2013), Zhong et al. (2016) }\end{array}$ \\
\hline & Seleção de fornecedores & $\begin{array}{l}\text { Lin et al. (2005), Kaynak e Hartley (2008) } \\
\text { Zeng, Phan e Matsui (2013), Lin, Kuei e Chai } \\
\text { (2013), Zagha (2009) }\end{array}$ \\
\hline & $\begin{array}{l}\text { Relação com } \\
\text { fornecedores }\end{array}$ & $\begin{array}{l}\text { Zeng, Phan e Matsui (2013), Foster Jr. (2008) } \\
\text { Robinson e Malhotra (2005), Zagha (2009) }\end{array}$ \\
\hline \multirow{2}{*}{ 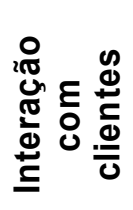 } & Foco no cliente & $\begin{array}{l}\text { Foster Jr. (2008), Lin, Kuei e Chai (2013), } \\
\text { Kaynak e Hartley (2008), Zhong et al. (2016) }\end{array}$ \\
\hline & Relação com o cliente & $\begin{array}{l}\text { Lin et al. (2005), Zeng, Phan e Matsui (2013) } \\
\text { Robinson e Malhotra (2005) }\end{array}$ \\
\hline
\end{tabular}

Fonte: Elaborado pelos autores. 


\section{PROCEDIMENTOS METODOLÓGICOS}

O principal objetivo deste trabalho é analisar a gestão da qualidade no contexto da cadeia de suprimentos de uma indústria calçadista do estado da Paraíba. Dessa forma, as unidades de análise selecionadas para o desenvolvimento da pesquisa foram duas organizações: uma indústria calçadista (empresa focal) denominada de Empresa A e uma fábrica de laminados (fornecedor de primeira camada) chamada de Empresa $B$.

A Empresa A é uma organização de capital aberto e atua no segmento de calçados, vestuários e acessórios das seguintes marcas: Havaianas, Dupé, Topper, Rainha, Mizuno, Timberland e Sete Léguas. No Brasil, está sediada no estado de São Paulo e possui 14 unidades de produção, sendo 5 fábricas centrais e 7 fábricas satélites; há ainda unidades de produção instaladas na Argentina e 5 escritórios espalhados pelo mundo, nas cidades de Nova York, Madri, Londres, Bolonha, Paris e Lisboa. Essa pesquisa foi desenvolvida em uma unidade localizada no estado da Paraíba em uma central de produção de artigos esportivos.

A Empresa $B$ também é uma organização de capital aberto que atua no mercado nacional e internacional, atendendo aos seguintes segmentos de mercado: calçados, bolsas e acessórios, utilidades domésticas, impermeabilização, móveis, vestuário, automotivo, puericultura, esporte e lazer, brindes, escolar e comunicação visual. São 9 empresas que compõem o grupo (entre fábricas, escritório e distribuidora), sendo que a unidade de estudo, também localizada no estado da Paraíba, é responsável pela produção de laminados que estão presentes nos cabedais e forros de calçados, bolsas e acessórios e nos revestimentos de estofados e interiores de carros.

Considerando o exposto, esta pesquisa adotou o método de multicasos, que, de acordo com Yin (2001), refere-se ao estudo de mais de um experimento (caso único), sendo que eles devem seguir uma lógica de replicação. Ainda de acordo com o autor, os resultados obtidos por meio do estudo de casos múltiplos são mais convincentes, sendo, portanto, considerados mais robustos que os resultados do estudo de caso único. No entanto, o estudo de casos múltiplos normalmente exige maior tempo e recursos por parte do pesquisador.

A pesquisa foi composta por cinco etapas principais, apresentadas no Quadro 3, onde também podem ser visualizados os diferentes instrumentos de coleta de dados. Segundo Yin (2001), a importância da utilização de variadas fontes para a obtenção de evidências nos estudos de caso está na possibilidade de obter-se convergência de informações de diferentes origens. Assim, as conclusões do estudo de caso tornamse mais convincentes e confiáveis. Na sequência é descrita a forma como cada etapa foi realizada. 


\section{Quadro 3 - Etapas da pesquisa}

\begin{tabular}{|c|c|c|}
\hline Etapas & Atividades & $\begin{array}{l}\text { Instrumento de Coleta de } \\
\text { Dados / Análise de dados }\end{array}$ \\
\hline I - Referencial teórico & $\begin{array}{l}\text { - Pesquisa em livros, monografias, } \\
\text { teses e dissertações sobre o tema; } \\
\text { - Pesquisa em artigos disponibilizados } \\
\text { na base de dados Web of Science. }\end{array}$ & - Pesquisa bibliográfica. \\
\hline $\begin{array}{l}\text { II - Desenvolvimento do } \\
\text { procedimento de análise }\end{array}$ & $\begin{array}{l}\text { - Elaboração do procedimento de } \\
\text { análise para auxiliar na coleta de dados } \\
\text { e na análise dos resultados da } \\
\text { pesquisa de campo. }\end{array}$ & - Pesquisa bibliográfica. \\
\hline $\begin{array}{l}\text { III - Pesquisa de campo } \\
\text { na empresa focal }\end{array}$ & $\begin{array}{l}\text { - Identificação das práticas internas de } \\
\text { gestão da qualidade da empresa focal; } \\
\text { - Identificação das características do } \\
\text { relacionamento da empresa focal com } \\
\text { seus fornecedores. }\end{array}$ & $\begin{array}{l}\text { - Entrevista semiestruturada; } \\
\text { - Observação participante; } \\
\text { - Análise documental. }\end{array}$ \\
\hline $\begin{array}{l}\text { IV - Pesquisa de campo } \\
\text { na empresa fornecedora }\end{array}$ & $\begin{array}{l}\text { - Identificação das práticas internas de } \\
\text { gestão da qualidade do fornecedor de } \\
\text { primeira camada; } \\
\text { - Identificação das características do } \\
\text { relacionamento do fornecedor de } \\
\text { primeira camada com a empresa focal. }\end{array}$ & $\begin{array}{l}\text { - Entrevista semiestruturada } \\
\text { - Observação passiva. }\end{array}$ \\
\hline $\begin{array}{l}V \text { - Análise dos } \\
\text { resultados }\end{array}$ & $\begin{array}{l}\text { - Análise das informações coletadas na } \\
\text { pesquisa de campo. }\end{array}$ & $\begin{array}{l}\text { - Análise do conteúdo das } \\
\text { informações. }\end{array}$ \\
\hline
\end{tabular}

Fonte: Elaborado pelos autores.

Na etapa I, revisão da literatura, inicialmente foi realizada uma busca em livros, dissertações, teses e artigos científicos (nacionais e interncionais) sobre a temática em estudo, de forma que se pudesse ter uma noção melhor do tema pesquisado. Posteriormente, o levantamento da literatura se concentrou em uma uma revisão sistemática que, segundo Stechemesser e Guenther (2012), é um método que auxilia na localização de pesquisas de forma abrangente e ajuda a sintetiza-las, utilizando procedimentos aplicáveis nas etapas do processo. As etapas da revisão sistemática realizada para este artigo podem ser visualizadas na Figura 1. 
Figura 1 - Etapas da revisão sistemática

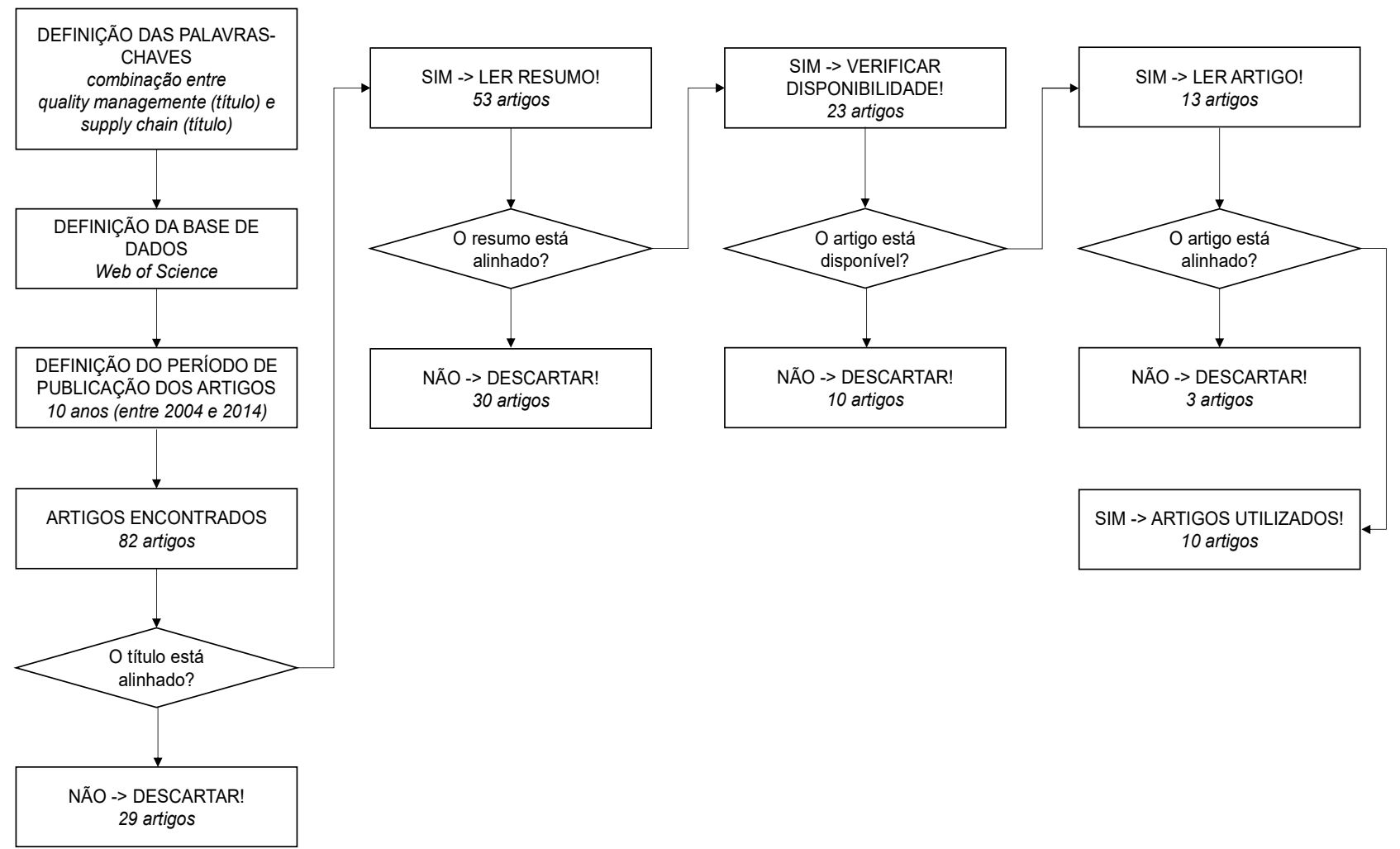

Fonte: Elaborado pelos autores.

A base de dados utilizada para realizar a revisão sistemática foi a Web of Science. Utilizando simultaneamente as palavras-chaves "quality management", no título, e "supply chain", também no título, entre os anos de 2004 e 2017, foram encontrados 82 trabalhos relacionados à temática. No entanto, após a realização de todos os filtros, restaram 10 artigos que tratavam do tema SCQM. Além destes, dois trabalhos considerados relevantes foram incluídos no portfólio de artigos a serem utilizados para o desenvolvimento da pesquisa.

Já o desenvolvimento do procedimento de análise (etapa II) foi construído tomando como base a divisão da gestão da qualidade no contexto da cadeia de suprimentos em três componentes (práticas internas, interação com fornecedores e interação com clientes), conforme a definição de Zeng, Phan e Matsui (2013). Entretanto, conforme destacado anteriormente, nesta pesquisa a interação com os clientes não foi abordada. No Quadro 4 podem ser visualizadas as categorias de análise utilizadas neste trabalho. 
Quadro 4 - Categorias de análise da pesquisa: práticas internas de qualidade e interação da qualidade com fornecedores

\begin{tabular}{|c|c|c|}
\hline Categoria & Descrição & Variáveis de Pesquisa \\
\hline $\begin{array}{c}\text { Liderança da } \\
\text { Gestão }\end{array}$ & $\begin{array}{l}\text { As lideranças contribuem com a } \\
\text { gestão da qualidade. }\end{array}$ & $\begin{array}{l}\text { - Apoio da diretoria, da gerência industrial e } \\
\text { dos gestores em relação às práticas de } \\
\text { qualidade. } \\
\text { - Obtenção de certificação de qualidade. }\end{array}$ \\
\hline $\begin{array}{l}\text { Gestão de } \\
\text { recursos } \\
\text { humanos }\end{array}$ & $\begin{array}{l}\text { Os colaboradores contribuem } \\
\text { com a gestão da qualidade. }\end{array}$ & $\begin{array}{l}\text { - Presença de grupos multifuncionais de } \\
\text { melhoria contínua. } \\
\text { - Participação dos colaboradores em } \\
\text { decisões de qualidade. } \\
\text { - Responsabilidade dos colaboradores } \\
\text { sobre falhas nos produtos. } \\
\text { - Reconhecimento dos colaboradores } \\
\text { sobre o trabalho desenvolvido com } \\
\text { qualidade. }\end{array}$ \\
\hline Treinamento & $\begin{array}{l}\text { Os colaboradores estão } \\
\text { capacitados a desenvolverem } \\
\text { seu trabalho com qualidade. }\end{array}$ & $\begin{array}{l}\text { - Conhecimento dos colaboradores sobre a } \\
\text { importância da qualidade para a empresa. } \\
\text { - Elaboração e apresentação de } \\
\text { treinamentos pelo setor de qualidade. }\end{array}$ \\
\hline $\begin{array}{l}\text { Design de } \\
\text { produtos }\end{array}$ & $\begin{array}{l}\text { O desenvolvimento de novos } \\
\text { produtos deve atender aos } \\
\text { padrões de qualidade. }\end{array}$ & $\begin{array}{l}\text { - Participação do setor de qualidade e } \\
\text { equipes multifuncionais no } \\
\text { desenvolvimento de novos produtos. } \\
\text { - Autonomia do setor de qualidade sobre } \\
\text { novos projetos. }\end{array}$ \\
\hline $\begin{array}{l}\text { Gestão de } \\
\text { processos }\end{array}$ & $\begin{array}{l}\text { A gestão da qualidade auxilia } \\
\text { na gestão de processos a fim } \\
\text { de garantir a qualidade dos } \\
\text { produtos e processos. }\end{array}$ & $\begin{array}{l}\text { - Realização de inspeção de produto } \\
\text { acabado. } \\
\text { - Realização de autoinspeção. } \\
\text { - Realização de auditorias de processo. } \\
\text { - Utilização de CEP. } \\
\text { - Formalização dos processos em forma de } \\
\text { procedimentos. }\end{array}$ \\
\hline $\begin{array}{l}\text { Dados de } \\
\text { qualidade }\end{array}$ & $\begin{array}{l}\text { Os dados obtidos pela } \\
\text { qualidade geram informações } \\
\text { para a tomada de ações. }\end{array}$ & $\begin{array}{l}\text { - Principais indicadores de qualidade. } \\
\text { - Disponibilidade e tratamento dos } \\
\text { indicadores de qualidade. } \\
\text { - Acompanhamento dos indicadores pelo } \\
\text { setor de qualidade. }\end{array}$ \\
\hline $\begin{array}{l}\text { Participação } \\
\text { dos } \\
\text { fornecedores } \\
\text { no design dos } \\
\text { produtos }\end{array}$ & $\begin{array}{l}\text { Os fornecedores tem } \\
\text { participação no } \\
\text { desenvolvimento de novos } \\
\text { produtos da empresa focal. }\end{array}$ & $\begin{array}{l}\text { - Forma como os fornecedores participam } \\
\text { do desenvolvimento de novos produtos. } \\
\text { - Existência de programa de } \\
\text { desenvolvimento de fornecedores. }\end{array}$ \\
\hline $\begin{array}{l}\text { Participação } \\
\text { dos } \\
\text { fornecedores } \\
\text { na melhoria } \\
\text { contínua }\end{array}$ & $\begin{array}{l}\text { Os fornecedores tem } \\
\text { participação na melhoria } \\
\text { contínua da qualidade da } \\
\text { empresa focal. }\end{array}$ & $\begin{array}{l}\text { - Solicitação de alterações de processo. } \\
\text { - Maneira de tratar problemas de qualidade } \\
\text { de matérias-primas. } \\
\text { - Participação dos fornecedores em grupos } \\
\text { de melhoria contínua da empresa focal. } \\
\text { - Participação full time de fornecedores na } \\
\text { empresa focal. } \\
\text { - Realização de auditorias no fornecedor. }\end{array}$ \\
\hline $\begin{array}{l}\text { Seleção de } \\
\text { fornecedores }\end{array}$ & $\begin{array}{l}\text { A empresa focal utiliza critérios } \\
\text { relacionados à qualidade na } \\
\text { seleção dos seus fornecedores. }\end{array}$ & $\begin{array}{l}\text { - Critérios de seleção de fornecedores. } \\
\text { - Exigência de certificação de qualidade } \\
\text { dos fornecedores. } \\
\text { - Quantidade de fornecedores. } \\
\text { - Realização de fornecimento exclusivo. }\end{array}$ \\
\hline $\begin{array}{l}\text { Relação com } \\
\text { fornecedores }\end{array}$ & $\begin{array}{l}\text { A empresa focal estabelce um } \\
\text { bom relacionamento com seus } \\
\text { fornecedores. }\end{array}$ & $\begin{array}{l}\text { - Longevidade dos relacionamentos com os } \\
\text { fornecedores. } \\
\text { - Estabelecimento de parceria nos } \\
\text { relacionamentos. } \\
\text { - Formas de avaliação das matérias- } \\
\text { primas. } \\
\text { - Presença dos fornecedores na empresa } \\
\text { focal para avaliar problemas de qualidade. }\end{array}$ \\
\hline
\end{tabular}

Fonte: Elaborado pelos autores. 
As etapas III e IV consistem no desenvolvimento do estudo empírico, que foi realizado no mês de julho a agosto de 2014 por meio entrevistas semiestruturadas, elaboradas tomando como base as categorias de análise apresentadas no Quadro 4. Todas as entrevistas foram gravadas e duraram, em média, cinquenta minutos.

$\mathrm{Na}$ empresa focal foram entrevistados três colaboradores: o gerente de qualidade da unidade, com tempo de atuação na empresa de 6 anos, sendo 3 no setor de gestão e desenvolvimento de fornecedores (GDF) e 3 no setor de qualidade; e dois analistas seniores, um com 6 e outro com 7 anos de empresa, todo o tempo no setor de qualidade. Além da entrevista, foi possível realizar análise documental para constatar a veracidade das informações obtidas, também auxiliada pela observação participante, pois uma das pesquisadoras participou da atividade que estava sendo pesquisada na empresa focal. $\mathrm{Na}$ empresa fornecedora foram entrevistados dois colaboradores: o assistente da qualidade, responsável pelo sistema de gestão da qualidade (SGQ), com tempo de atuação na empresa de 10 meses; e um assistente do controle de qualidade (CQ), que atua na empresa há 14 anos. Neste caso, as entrevistas aconteceram juntamente com a observação passiva. Os entrevistados foram enumerados de 1 a 5 a fim de manter a identificação sigilosa à medida em que são mencionados no texto.

$\mathrm{Na}$ etapa $\mathrm{V}$, última etapa da pesquisa, de posse das informações obtidas na pesquisa de campo, as análises foram realizadas por meio do método de análise de conteúdo, no qual as informações obtidas empiricamente são relacionadas e associadas aos elementos encontrados no referencial teórico. $\mathrm{O}$ desenvolvimento do procedimento de análise foi extremamente importante nesta etapa, uma vez que foram selecionadas e agrupadas categorias de análise para a aplicação da pesquisa de campo.

\section{RESULTADOS E DISCUSSÃO}

Nesta seção os resultados serão apresentados e discutidos comparando-se as características das categorias de análise investigadas nas empresas A e B e identificando-se algumas possibilidades de melhorias.

\section{Práticas Internas de Gestão da Qualidade}

Por meio da pesquisa de campo foi possível verificar que as duas empresas realizam práticas internas de gestão da qualidade bastante semelhantes, considerando, evidentemente, a diferença entre os processos produtivos e a finalidade dos produtos fabricados. A empresa focal possui uma estrutura de gestão da qualidade um pouco mais consolidada do que a da empresa fornecedora, mesmo esta possuindo a certificação ISO 9000. Isso porque, mesmo não obtendo a certificação, a empresa focal realiza seus controles internos com robustez, seguindo alguns requisitos que a própria norma indica como formas de garantia da qualidade. No Quadro 5 podem ser visualizadas, de forma resumida, as práticas internas de qualidade utilizadas pelas duas empresas. 
Quadro 5 - Práticas internas de qualidade das empresas A e B

\begin{tabular}{|c|c|c|}
\hline $\begin{array}{l}\text { Práticas Internas de } \\
\text { Gestão da } \\
\text { Qualidade }\end{array}$ & Empresa A & Empresa B \\
\hline $\begin{array}{l}\text { Liderança da } \\
\text { gestão }\end{array}$ & $\begin{array}{l}\text { - A diretoria e a gerência industrial } \\
\text { apoiam as práticas de qualidade. } \\
\text { - O apoio e a participação dos } \\
\text { gestores ainda não é efetiva. }\end{array}$ & $\begin{array}{l}\text { - A diretoria e a gerência industrial } \\
\text { apoiam as práticas de qualidade. } \\
\text { - O apoio e a participação dos } \\
\text { gestores ainda não é efetiva. }\end{array}$ \\
\hline $\begin{array}{c}\text { Gestão de recursos } \\
\text { humanos }\end{array}$ & $\begin{array}{l}\text { - A formação de grupos de melhoria } \\
\text { contínua é uma prática consolidada. } \\
\text { - Não há reconhecimento dos } \\
\text { colaboradores pelo trabalho } \\
\text { desenvolvido com qualidade. }\end{array}$ & $\begin{array}{l}\text { - A formação de grupos de melhoria } \\
\text { contínua não é uma prática } \\
\text { consolidada. } \\
\text { - Não há reconhecimento dos } \\
\text { colaboradores pelo trabalho } \\
\text { desenvolvido com qualidade. }\end{array}$ \\
\hline Treinamento & $\begin{array}{l}\text { - A maior parte dos treinamentos } \\
\text { realizados pelo setor de qualidade } \\
\text { são voltados para a própria equipe de } \\
\text { qualidade, havendo deficiência nos } \\
\text { treinamentos voltados para o } \\
\text { processo produtivo. }\end{array}$ & $\begin{array}{l}\text { - Esporadicamente a qualidade } \\
\text { realiza treinamentos com os } \\
\text { colaboradores dos setores } \\
\text { produtivos. }\end{array}$ \\
\hline Design de produtos & $\begin{array}{l}\text { - O setor de qualidade tem } \\
\text { participação decisiva no } \\
\text { desenvolvimento de novos produtos. }\end{array}$ & $\begin{array}{l}\text { - O setor de qualidade tem } \\
\text { participação decisiva no } \\
\text { desenvolvimento de novos } \\
\text { produtos. }\end{array}$ \\
\hline $\begin{array}{l}\text { Gestão de } \\
\text { processos }\end{array}$ & $\begin{array}{l}\text { - Há forte participação da inspeção do } \\
\text { produto acabado. } \\
\text { - São realizadas auditorias de } \\
\text { processo com bastante frequência. } \\
\text { - A empresa não utiliza o CEP. } \\
\text { - Há um bom sistema de formalização } \\
\text { dos procedimentos. }\end{array}$ & $\begin{array}{l}\text { - A inspeção é feita durante o } \\
\text { processo produtivo; mesmo assim, } \\
\text { é realizada a revisão final. } \\
\text { - São realizadas auditorias de } \\
\text { acompanhamento interno e } \\
\text { auditorias exigidas pela norma de } \\
\text { qualidade. } \\
\text { - A empresa não utiliza o CEP. } \\
\text { - Há um bom sistema de } \\
\text { formalização dos procedimentos. }\end{array}$ \\
\hline Dados de qualidade & $\begin{array}{l}\text { - A empresa possui indicadores de } \\
\text { qualidade bem definidos, } \\
\text { disponibilizando-os para que os } \\
\text { setores tomem ações de melhoria. }\end{array}$ & $\begin{array}{l}\text { - O setor de qualidade atua no } \\
\text { acompanhamento dos indicadores } \\
\text { dos demais setores, } \\
\text { disponibilizando-os para que cada } \\
\text { um tome as devidas ações de } \\
\text { melhoria. }\end{array}$ \\
\hline
\end{tabular}

Fonte: Elaborado pelos autores.

Em relação à liderança da gestão, foi possível constatar que tanto a diretoria quanto a gerência industrial de ambas as empresas apoiam as práticas de qualidade. Como afirmam Lin et al. (2005), essa participação é de extrema importância, pois permite as condições necessárias para a implementação da gestão da qualidade. Por se tratarem de colaboradores que estão situados no nível estratégico das empresas, os diretores e os gerentes industriais conhecem a importância de fabricar produtos de qualidade para que as empresas se mantenham competitivas no mercado.

Em contrapartida, o apoio dos gestores em relação à qualidade não é tão efetivo como o da liderança de topo, visto que, na maioria das situações, os gestores de processo buscam atender ao volume de produção em detrimento à qualidade. Na Empresa A, por exemplo, de acordo com o Entrevistado 1, "muitas vezes o gestor resolve fechar o olho para a qualidade para atender a quantidade que precisa ser produzida e isso acaba contaminando a equipe de supervisores, a liderança e reflete na produção como um todo". $O$ Entrevistado 2 corrobora com esse pensamento, afirmando que os gestores participam muito mais para 
atingirem as metas do que por acreditarem que a qualidade é importante, ou seja, por considera-la uma premissa da empresa. Já o Entrevistado 3 afirma que mesmo com essas dificuldades, é possível perceber que a cobrança tem ajudado na participação, pois os gestores é que são responsáveis por promoverem melhorias, até porque "um indicador que está abaixo não é um problema do setor de qualidade, mas um problema dos gestores de produção" (ENTREVISTADO 3). Já na Empresa B, o Entrevistado 4 informou que percebe que os gestores estão bastante envolvidos com a qualidade nos últimos tempos, mas não sabe se isso se deu devido à empresa ter passado recentemente pela recertificação ou se com o tempo essa prática irá "esfriar".

Essa visão dos gestores precisa ser transformada pela cultura da qualidade descrita nas políticias de qualidade das empresas, fazendo-os compreender que produzir sem qualidade gera produtos parados no estoque, pois o mercado atual não os absorvem. De certa forma, a certificação de qualidade auxilia a empresa fornecedora a realizar essa mudança de cultura.

Em relação à gestão de recursos humanos, foi possível perceber que a formação de grupos multifuncionais é uma prática que traz bons resultados para ambas as empresas. Na Empresa A, os grupos são abertos a fim de resolver os principais problemas que tem ocorrido em determinado período, cujas causas raízes não são conhecidas e precisam de investigação; os grupos seguem a metodologia do MASP (método de análise e solução de problemas). A Empresa B não possui círculos de qualidade pré-definidos. Assim, quando acontece determinado problema que não pode ser resolvido de imediato, são formados grupos por um curto período de tempo. O Entrevistado 4 afirmou que há pouco tempo atrás não ocorria dessa forma (cada ação possuía um único responsável), mas que o formato desses grupos dinâmicos tem dado melhores resultados. A formação dos grupos permite o compartilhamento do conhecimento e, consequentemente, a maior eficácia das ações.

Sobre as decisões de qualidade por parte dos setores produtivos, na Empresa A, os supervisores, líderes e operadores só tem autonomia para decidir aquilo que está aprovado ou reprovado com base nos manuais de qualidade disponibilizados. Isso significa que alterações no processo precisam passar pela avaliação das áreas de apoio, como qualidade e laboratório (ENTREVISTADO 3). Na empresa fornecedora, por esta possuir um processo bastante automatizado e complexo, os operadores do setor produtivo não participam diretamente de decisões de qualidade, seguindo as especificações presentes na ordem de serviço.

Ainda na Empresa $A$, quanto à responsabilidade por falhas de qualidade e ao reconhecimento dos trabalhadores pelo trabalho desenvolvido com qualidade, os Entrevistados 2 e 3 citaram o PPR (plano de participação nos resultados) como uma forma de realizar essa avaliação, o que ocorre de maneira coletiva (reconhecimento do grupo), não havendo um reconhecimento individual. O Entrevistado 1 afirma que "como muitas vezes vivemos de apagar os incêndios, acabamos não planejando isso". Na Empresa B, o programa de premiação, PPM (programa de participação de melhoria), possui metas mensais, mas há um fator condicionante conforme o resultado operacional da empresa que pode reduzir a premiação.

Dessa forma, a possibilidade de melhoria desta categoria está no reconhecimento dos trabalhadores pelo trabalho desenvolvido com qualidade, o que atualmente não é uma prática consolidada nas empresas. Além disso, é preciso incentivar o maior envolvimento dos colaboradores com a qualidade, pois, como afirmam Lin et al. (2005), a qualidade depende dos esforços de todos os funcionários. 
Em relação à categoria treinamento, verifica-se na Empresa A que os colaboradores, especialmente os operadores de produção, reconhecem a qualidade como algo importante, mas muito mais com a visão de consumidor, pois "todo mundo concorda que ninguém quer comprar um produto sem qualidade" (ENTREVISTADO 3). Assim, o setor de qualidade da Empresa A atua na elaboração e apresentação de treinamentos, tanto para a própria equipe de qualidade quanto para os colaboradores do processo produtivo, mas neste caso muito mais de acordo com a disponibilidade do pessoal da produção. O Entrevistado 1 cita dois pontos que precisam ser melhorados na Empresa 1 em relação a essa categoria: o primeiro é que os treinamentos técnicos geralmente são passados por pessoas experientes na operação, que se não tem a qualidade como um princípio básico possivelmente irá passar as informações sem considerá-la; o segundo é que geralmente os treinamentos são realizados no final do turno, quando os colaboradores já se apresentam fatigados e não absorvem de forma efetiva o que está sendo transmitido.

$\mathrm{Na}$ Empresa B, o Entrevistado 4 defendeu que "cada um se sente responsável por fazer o produto com qualidade, sabe a importância disso". No entanto, nessa empresa o SGQ não possui um cronograma específico que define o planejamento para a realização de treinamentos, ocorrendo esporadicamente de acordo com a necessidade do processo ou sobre algum tema relacionado à ISO. Os funcionários do CQ são treinados para realizarem os testes de garantia de qualidade do produto. Os novos operadores recebem treinamento de acordo com um procedimento específico, conforme estabelecido na norma.

Visto que a qualidade depende da participação dos colaboradores, para que haja esse envolvimento é preciso que cada funcionário reconheça a importância de realizar a sua operação com qualidade e, para isso, como indicam Zeng, Phan e Matsui (2013), é necessário fornecer treinamentos relacionados com a qualidade voltados para a tarefa. As duas empresas carecem desse tipo de atividade para tornar concreta a participação dos colaboradores, especialmente dos setores produtivos, na garantia da qualidade.

É possível perceber que as categorias de análise relacionadas às pessoas (liderança da gestão, gestão de recursos humanos e treinamento) afetam diretamente a gestão da qualidade das empresas, especialmente a Empresa A. São diversas as características que podem comprometer o bom desempenho da qualidade, como: descompromisso com a atividade, alta rotatividade dos trabalhadores; medo de "perder" o cargo por aceitar boas ideias de outros colegas; aceitação de produtos não conformes para atender ao volume de produção; disseminação da má cultura da qualidade. Essas questões merecem maior atenção dos gestores para que efetivamente as práticas de qualidade gerem melhorias aos processos e aos produtos.

Em relação ao design de novos produtos, na Empresa $A$, o setor de qualidade atua no acompanhamento das validações, quando são produzidos 6 pares de uma única numeração, e da produção da OP piloto, composta por 288 pares distribuídos entre todas as numerações. Há um analista da qualidade (analista de lançamentos) responsável por acompanhar essas etapas, utilizando um checklist com os pontos críticos para a qualidade do produto. As etapas de validação e de produção do lote piloto servem, por exemplo, para verificar se é possível fabricar o produto atendendo aos requisitos de qualidade. $\mathrm{O}$ setor de qualidade tem o encargo de enviar o relatório de avaliação final, aprovando ou reprovando o projeto, o que significa que nenhum projeto é autorizado para a produção em série sem o aval da qualidade.

$\mathrm{Na}$ Empresa B, a participação do $\mathrm{CQ}$ no desenvolvimento de novos produtos ocorre na realização de testes nas amostras produzidas pelo setor de desenvolvimento, o DNP (desenvolvimento de novos produtos). O Entrevistado 4 mencionou que para este setor afirmar que determinado produto está aprovado, é preciso 
que o CQ também tenha aprovado o material. Assim, em ambas as empresas a qualidade atua de forma efetiva nesse processo, avaliando o aspecto visual e/ou realizando testes que garantam o atendimento às especificações.

Em relação à gestão de processos, foi verificado que a Empresa A realiza uma grande quantidade de inspeções para evitar que o produto chegue ao consumidor final apresentando defeitos. Os Entrevistados 1 e 3 defendem que essa participação é devido à característica massivamente manufatureira do produto que é fabricado. O Entrevistado 1 afirma que "são muitas mãos por onde passa cada peça do calçado, então é muito fácil de se errar, é muito fácil desobedecer as referências". Por isso, a inspeção torna-se uma ferramenta fundamental no controle de qualidade do produto na Empresa $\mathrm{A}$.

Mesmo assim, segundo os Entrevistados 1, 2 e 3 da Empresa A, os indicadores mostram que há um grande volume de calçados devolvidos por apresentarem defeitos de fabricação. Além disso, é grande a quantidade de produtos que são retrabalhados e até mesmo inutilizados devido a problemas de qualidade na fabricação na empresa focal. Assim, a empresa despende recursos em uma atividade que não sana o problema, servindo como um paleativo para evitar maiores transtornos. Nesse quesito é preciso que a gestão da qualidade da Empresa $A$ atue fortemente na cultura da auto inspeção em contrapartida à dependência da inspeção, como defendem Kaynak e Hartley (2008), o que acontece de forma satisfatória na empresa fornecedora analisada.

A realização de auditorias internas na Empresa $A$, como uma forma de realizar o controle dos processos, é uma atividade que auxilia na identificação de não conformidades no momento em que são geradas. Por mais que este seja um bom mecanismo de controle, é possível que os colaboradores dos setores produtivos "arrumem" o processo para receber a auditoria e os resultados não sejam compatíveis com a realidade, o que não garante o atendimento às especificações. Destaca-se, portanto, a importância da conscientização dos trabalhadores no que diz respeito à qualidade e à cultura da auto inspeção. As auditorias realizadas na Empresa $B$ são estabelecidas pela norma de qualidade, podendo correr o mesmo risco de "camuflar" a realidade; no entanto, devido às exigências da norma e à cobrança pelas recertificações, os colaboradores estão bem mais envolvidos nesse processo. Nenhuma das empresas utiliza o CEP (controle estatístico de processo) em suas atividades.

Em ambas as empresas há um bom sistema de formalização dos processos e atividades no formato de procedimentos, o que proporciona uma melhor organização das informações e o acúmulo do conhecimento gerado. O que deve ser garantida é a atualização desses documentos de acordo com o que realmente acontece no dia a dia de trabalho, para que não se tornem informações sem finalidade. Além disso, é preciso que os colaboradores conheçam bem esses procedimentos e possam consultá-los sempre que for necessário.

Por fim, no que se refere aos dados de qualidade, percebe-se que o setor de qualidade das duas empresas acompanha o andamento dos indicadores e disponibiliza-os para os demais setores, discutindo-os também em reuniões com os gestores. Kaynak e Hartley (2008) apontam que esse feedback é de extrema importância para a resolução de problemas. Paladini (2011) corrobora afirmando que um aspecto importante da gestão da qualidade está na avaliação e mensuração de indicadores que apontem a evolução das melhorias a partir de ações que promovem a qualidade, tanto em relação aos métodos quanto em relação aos processos e produtos. De fato, isso é muito importante para que todos tenham conhecimento dos principais problemas ocorridos e dos picos apresentados pelos indicadores, mas vale acrescentar que o setor 
de qualidade deve atuar garantindo a confiabilidade desses dados e acompanhando se ações concretas são tomadas para controlar e até mesmo sanar as dificuldades.

Tomando como base o exposto, o Quadro 6 foi desenvolvido de forma a apresentar os principais pontos de melhoria identificados na análise realizada.

\section{Quadro 6 - Possibilidades de melhoria nas práticas internas de qualidade nas empresas A e B}

\begin{tabular}{|l|c|c|}
\hline \multicolumn{1}{|c|}{ Pontos de Melhoria } & Empresa A & Empresa B \\
\hline $\begin{array}{l}\text { Conscientizar os gestores sobre a importância de fabricar produtos } \\
\text { com qualidade, equilibrando o atendimento à carteira de produção } \\
\text { com as exigências de qualidade do consumidor. }\end{array}$ & $\mathrm{X}$ & $\mathrm{X}$ \\
\hline $\begin{array}{l}\text { Fortalecer a prática de formação de grupos multifuncionais para } \\
\text { análise e resolução de problemas. }\end{array}$ & $\mathrm{X}$ & $\mathrm{X}$ \\
\hline $\begin{array}{l}\text { Proporcionar maior envolvimento e participação dos colaboradores } \\
\text { com a qualidade. }\end{array}$ & $\mathrm{X}$ & $\mathrm{X}$ \\
\hline $\begin{array}{l}\text { Elaborar formas de reconhecer os colaboradores pelo trabalho } \\
\text { desenvolvido com qualidade. }\end{array}$ & $\mathrm{X}$ & $\mathrm{X}$ \\
\hline $\begin{array}{l}\text { Elaborar e apresentar treinamentos com foco na qualidade da tarefa } \\
\text { para os colaboradores dos setores produtivos. }\end{array}$ & $\mathrm{X}$ & $\mathrm{X}$ \\
\hline Fortalecer a cultura da auto inspeção. & $\mathrm{X}$ & $\mathrm{X}$ \\
\hline $\begin{array}{l}\text { Verificar a possibilidade da utilização do CEP para identificar e reduzir } \\
\text { as variabilidades do processo produtivo. }\end{array}$ & $\mathrm{X}$ & $\mathrm{X}$ \\
\hline $\begin{array}{l}\text { Garantir a atualização dos documentos e procedimentos de acordo } \\
\text { com a realidade das atividades formalizadas. }\end{array}$ & $\mathrm{X}$ & \\
\hline Garantir a confiabilidade dos dados que geram os indicadores. & $\mathrm{X}$ & \\
\hline $\begin{array}{l}\text { Acompanhar o cumprimentos das ações encaminhadas para os } \\
\text { gestores. }\end{array}$ & & \\
\hline
\end{tabular}

Fonte: Elaborado pelos autores.

Zeng, Phan e Matsui (2013) afirmam que é necessário a aplicação eficaz das práticas internas de gestão da qualidade para que as empresas possam avançar na colaboração e interação da qualidade no sentidos upstream e downstream da cadeia de suprimentos. Por isso, é necessário que as empresas investigadas consolidem a gestão interna da qualidade para, assim, verificar os reais benefícios de interagir com seus fornecedores no que diz respeito à qualidade. Dentre os benefícios gerados, de acordo com Zu e Kaynak (2012), destaca-se a melhoria da satisfação dos clientes.

Assim, para que a gestão da qualidade seja melhorada nas duas empresas é necessário em um primeiro momento que ambas melhorem suas práticas internas (de acordo com as sugestões apresentadas no Quadro 6). A partir disso, as empresas terão condições de poder enxergar os reais benefícios de agir de forma colaborativa e integrada entre os seus parceiros, conforme afirmam Zeng, Phan e Matsui (2013).

\section{Interação da Qualidade entre as Empresas}

Por meio da pesquisa de campo na Empresa A constatou-se que esta possui uma estrutura bem consolidada de relacionamento com seus fornecedores, especialmente por possuir um setor destinado a isso, composto por uma equipe de GDF. O setor de qualidade também participa ativamente desse relacionamento, atuando na verificação do atendimento das matérias-primas às especificações. No Quadro 7 está apresentada, de maneira resumida, a forma como a Empresa A visualiza o relacionamento com o fornecedor pesquisado e vice-versa. 
Quadro 7 - Interação da qualidade entre as empresas A e B

\begin{tabular}{|c|c|c|}
\hline $\begin{array}{c}\text { Interação da } \\
\text { Qualidade entre as } \\
\text { Empresas }\end{array}$ & Empresa A & Empresa B \\
\hline $\begin{array}{c}\text { Participação dos } \\
\text { fornecedores no design } \\
\text { de produtos }\end{array}$ & $\begin{array}{l}\text { - A empresa focal apresenta os } \\
\text { requisitos ou fornece uma amostra } \\
\text { do produto que deseja que os } \\
\text { fornecedores desenvolvam. } \\
\text { - Para ser fornecedor da empresa } \\
\text { focal é preciso atender a requisitos } \\
\text { legais, trabalhistas e ambientais. } \\
\text { - Há a possibilidade da empresa } \\
\text { focal injetar capital para desenvolver } \\
\text { os fornecedores. } \\
\text { - O fornecedor nunca participa da } \\
\text { etapa de validação de novos } \\
\text { produtos da empresa focal para } \\
\text { evitar a disseminação de } \\
\text { informações para os concorrentes. }\end{array}$ & $\begin{array}{l}\text { - A Empresa B desenvolve } \\
\text { amostras de acordo com amostras } \\
\text { apresentadas pela Empresa A ou } \\
\text { de acordo com as especificações } \\
\text { solicitadas. }\end{array}$ \\
\hline $\begin{array}{l}\text { Participação dos } \\
\text { fornecedores na } \\
\text { melhoria contínua }\end{array}$ & $\begin{array}{l}\text { - A empresa focal não exige que } \\
\text { seus fornecedores façam alterações } \\
\text { diretamente no processo, mas no } \\
\text { produto. } \\
\text { - Há a possibilidade da empresa } \\
\text { focal traçar um plano de ação junto } \\
\text { com os fornecedores para } \\
\text { solucionar problemas. } \\
\text { - Se determinado fornecedor não } \\
\text { resolver rapidamente problemas no } \\
\text { seu processo para garantir a } \\
\text { qualidade da matéria-prima, a } \\
\text { empresa focal busca outra fonte de } \\
\text { fornecimento. } \\
\text { - Os fornecedores podem participar } \\
\text { efetivamente dos grupos de } \\
\text { melhoria contínua da empresa focal. }\end{array}$ & $\begin{array}{l}\text { - A empresa A não exige que a } \\
\text { Empresa B faça alterações } \\
\text { diretamente no processo, mas no } \\
\text { produto. } \\
\text { - A Empresa B não participa de } \\
\text { grupos de melhoria contínua da } \\
\text { empresa focal. }\end{array}$ \\
\hline $\begin{array}{c}\text { Seleção de } \\
\text { fornecedores }\end{array}$ & $\begin{array}{l}\text { - A qualidade pode sobressair ao } \\
\text { preço na seleção de fornecedores. } \\
\text { - A certificação de qualidade não é } \\
\text { uma exigência para o fornecimento. } \\
\text { - Mesmo possuindo a certificação } \\
\text { de qualidade, a Empresa B passou } \\
\text { pelo processo de homologação da } \\
\text { empresa focal. } \\
\text { - O mesmo material não é } \\
\text { comprado de mais de um } \\
\text { fornecedor simultaneamente. } \\
\text { - Há fornecimento de materiais } \\
\text { exclusivos. } \\
\text { - Acredita-se que é ruim ter poucos } \\
\text { fornecedores homologados do } \\
\text { mesmo material. }\end{array}$ & $\begin{array}{l}\text { - Acredita-se que o preço pode ser } \\
\text { mais importante que a qualidade. } \\
\text { - Acredita-se que a empresa focal } \\
\text { exige certificação de qualidade } \\
\text { dos seus fornecedores. } \\
\text { - Há fornecimento de materiais } \\
\text { exclusivos. }\end{array}$ \\
\hline $\begin{array}{l}\text { Relação com } \\
\text { fornecedores }\end{array}$ & $\begin{array}{l}\text { - A empresa focal possui uma área } \\
\text { destinada a lidar com fornecedores, } \\
\text { a equipe de GDF. } \\
\text { - Acredita-se que há relacionamento } \\
\text { de parceria entre a empresa e seus } \\
\text { fornecedores. } \\
\text { - A empresa focal recebe visitas dos } \\
\text { fornecedores para avaliar } \\
\text { problemas de qualidade das } \\
\text { matérias-primas fornecidas. }\end{array}$ & $\begin{array}{l}\text { - A Empresa B realiza visitas na } \\
\text { Empresa A para avaliar problemas } \\
\text { de qualidade das matérias-primas } \\
\text { fornecidas. } \\
\text { - Acredita-se, em parte, que a } \\
\text { Empresa B estabelece } \\
\text { relacionamento de parceria com a } \\
\text { Empresa A. }\end{array}$ \\
\hline
\end{tabular}

Fonte: Elaborado pelos autores. 
Em relação à categoria de participação dos fornecedores no desenvolvimento de novos produtos houve concordância entre todos os entrevistados (1, 2 e 3) sobre a forma como acontece essa interação. A participação nesta Empresa se dá no desenvolvimento de novas matérias-primas a partir das especificações solicitadas ou a partir de uma amostra fornecida pela empresa focal. De acordo com o Entrevistado 3 "... no caso de matérias-primas mais críticas, cuja qualidade impacta diretamente na qualidade do produto acabado, o fornecedor visita a fábrica para que o produto seja apresentado".

Kaynak e Hartley (2008) defendem que é muito importante os fornecedores darem assistência aos seus clientes no desenvolvimento de produtos, pois eles se tornam capazes de responder mais eficazmente às exigências dos compradores. Os fornecedores não participam da etapa de validação do novo calçado a fim de evitar que informações valiosas sejam repassadas para os concorrentes, o que demonstra que não existe um relacionamento de confiança entre as empresas que garanta a segurança das informações.

A Empresa A tem como premissa básica que seus fornecedores atendam aos requisitos legais de operação, a Empresa B precisa manter essa adequação para garantir o relacionamento, pois, por melhor que seja o seu produto em termos de qualidade, o não atendimento a essas condições cancela o fornecimento. Esse tipo de requisito é citado por Jraisat e Sawalha (2013) em seus estudos, quando analisam os fatores ambientais que influenciam o relacionamento entre os membros da cadeia de suprimentos. De certa forma, isso obriga a Empresa $\mathrm{B}$, assim como os demais fornecedores, a garantir a adequação a requisitos trabalhistas e ambientais, por exemplo, o que também pode ser considerado um fator crítico de qualidade.

A possibilidade da Empresa A injetar capital nos seus fornecedores para que eles se desenvolvam é uma característica bastante relevante no contexto de relacionamento da cadeia de suprimentos, podendo trazer vantagens competitivas para ambas as empresas. Jraisat e Sawalha (2013) citam o apoio financeiro como uma forma de viabilizar os negócios entre os membros da cadeia.

A participação dos fornecedores na melhoria contínua da Empresa A pode acontecer diretamente nos círculos de qualidade. Entretanto, a Empresa A não solicita diretamente que os fornecedores façam alterações no seu processo, pois, como afirma o Entrevistado 3 "...isso seria um risco devido à grande responsabilidade que a empresa assumiria". Os entrevistados da Empresa B afirmaram não conhecer esse tipo de atuação da empresa nos grupos de melhoria contínua, mas apenas nas visitas que são realizadas para avaliar problemas de qualidade. No entanto, a observação direta dos pesquisadores pôde comprovar que esse tipo de atuação acontece realmente, especialmente com fornecedores de adesivos e tintas, por exemplo. Como foi citado por Pires (2004), o fornecedor contribui para a qualidade do produto por meio do conhecimento e da experiência que traz, favorecendo a aprendizagem conjunta.

A possibilidade da Empresa A traçar planos de ação junto com os fornecedores para solucionar problemas de qualidade, realizando o acompanhamento da eficácia dessas ações, é uma forma de estreitar o relacionamento entre as empresas. No entanto, foi possível perceber que esta possui certa flexibilidade em trocar de fornecedor, caso o material fornecido esteja apresentando não conformidades, inclusive realizando o processo de contratipagem, no qual o material do atual fornecedor é passado para outro a fim de verificar se este atende às características da mesma forma. Isso demonstra que há um pouco de fragilidade nos relacionamentos, que pode ser rompido a qualquer momento. A Empresa A possui uma base de fornecedores que são homologados e ficam aguardando a requisição do fornecimento. Esse processo de homologação é vantajoso para a empresa focal, mas deixa a empresa fornecedora vulnerável à substituição, tornando-se até 
mesmo uma ameaça para esta empresa. Isso se contrapõe à relação ganha-ganha característica da cadeia de suprimentos.

Em contrapartida, verificou-se que pode acontecer das empresas fornecedoras produzirem materiais exclusivos para a Empresa A, como o próprio tipo de laminado que a Empresa B fornece. Essa característica da exclusividade contribui para o fortalecimento do relacionamento, pois de certa forma gera uma maior dependência que, como afirmaram Slack, Chambers e Johnston (2002), favorece o maior comprometimento e o foco nos esforços em atender aos requisitos da empresa solicitante.

Em relação ao processo de seleção de fornecedores, A Empresa A não exige que seus fornecedores possuam certificação de qualidade, pois de acordo com o Entrevistado 2 "a certificação serve como uma indicação, um diferencial para o fornecedor" mas na "política da empresa não está estabelecido que a certificação define se determinada empresa irá fornecer ou não" (ENTREVISTADO 3). Entretanto percebeuse que os Entrevistados 4 e 5 da Empresa $B$ acreditam que exista essa exigência. Isso demonstra que para os colaboradores desta empresa a norma é uma ferramenta primordial e de garantia do relacionamento com os seus clientes, quando na verdade foi percebido que não é, pelo menos no caso da Empresa A. Inclusive foi verificado que mesmo possuindo a norma, a Empresa $B$ passou pelo processo de homologação, o que demonstra que possuir a ISO não foi uma característica suficiente de escolha, mas certamente um diferencial, o que não anula a importância de obter a certificação.

Ainda em relação à seleção de fornecedores, as variáveis preço e qualidade são avaliadas conjuntamente, mas há casos em que a qualidade pode sobressair ao preço, de acordo com a criticidade do material e da abrangência que um desvio de qualidade pode provocar. Zeng, Phan e Matsui (2013) e Kaynak e Hartley (2008) defendem a importância de centrar a política de seleção de fornecedores em qualidade ao invés de preço.

Como a Empresa A possui uma área voltada para o relacionamento com os fornecedores (a equipe de GDF) acredita-se que isso possibilita o relacionamento de parceria entre as duas organizações. Entretanto, o Entrevistado 5 (Empresa B), discorda que as empresas sejam parceiras, pois afirma que há uma relação distanciada. Como não está definido em contrato o tempo do fornecimento, o desempenho do fornecedor é que vai determinar a longevidade do relacionamento. Segundo Pires (2004), a parceria ocorre quando há um alto nível de colaboração e integração de processos entre as empresas, o que ainda não está consolidado nas empresas estudadas.

Por fim, convém destacar que, apesar de a interação de qualidade entre as empresas ser consolidada, verificou-se que existem aspectos que precisam ser melhorados, como por exemplo, o estabelecimento de um relacionamento de confiança e de longo prazo. Conforme afirmam Robinson e Malhotra (2004), para implementar com sucesso práticas de intercâmbio de recursos e competências, é necessário confiança e isso pode orientar a eficiência, o desempenho e a qualidade em toda a cadeia de suprimentos. Fernandes et al. (2017) corroboram e afirmam que a melhoraria da qualidade na cadeia de suprimentos traz impactos positivos na utilização dos recursos e na eficiência dos processos. Portanto, de acordo com os autores, os parceiros de uma cadeia de suprimentos deveriam olhar para os benefícios da colaboração, de forma a ampliar o potencial de geração de vantagens competitivas conjuntas. 


\section{DISCUSSÃO E CONCLUSÕES}

O principal objetivo deste artigo foi analisar a gestão da qualidade no contexto da cadeia de suprimentos de uma indústria calçadista do estado da Paraíba (sendo uma empresa focal e um fornecedor de primeira camada). Para o alcance do objetivo foi desenvolvido um procedimento de análise com categorias de pesquisa e variáveis a serem investigadas. Esse procedimento foi desenvolvido com base na literatura consultada que, em grande parte, classifica as práticas de gestão da qualidade na cadeia de suprimentos em práticas internas, de interação com os fornecedores e clientes (sendo este último fora do escopo dessa pesquisa).

O desenvolvimento do procedimento constitui-se em uma das contribuições deste trabalho. Por meio deste, foi possível desenvolver os instrumentos de pesquisa para analisar as práticas internas de gestão da qualidade das duas empresas, identificando os pontos convergentes e divergentes entre elas e as principais possibilidades de melhorias. Este procedimento também permitiu analisar a interação da qualidade entre a empresa focal e a empresa fornecedora.

Os resultados obtidos por meio da aplicação do procedimento de análise vem de encontro aos achados de Zhong et al. (2016), pois verificou-se que a adoção de práticas internas de gestão da qualidade também influenciam na interação da qualidade entre as empresas, mesmo que as práticas internas necessitem de melhorias, conforme se verificou neste trabalho por meio da apresentação do Quadro 6. Por meio da pesquisa, também foi possível constatar que a confiança é um dos elementos mais importantes para o melhor gerenciamento da qualidade na cadeia de suprimentos, corroborando com os resultados obtidos de Robinson e Malhotra (2004). A confiança é fundamental para a colaboração na cadeia (DYER; SINGH, 1998) sendo que a colaboração auxilia na melhoria dos processos de gestão da qualidade, na integração da cadeia e, consequentemente no desenvolvimento de vantagens competitivas conjuntas. Entretanto, a confiança entre as empresas foco de investigação precisa ser melhorada, sendo que tal melhoria poderá trazer impactos positivos para a gestão da qualidade da cadeia como um todo.

O desenvolvimento deste artigo também contribuiu para o avanço do conhecimento em relação à gestão da qualidade no contexto da gestão da cadeia de suprimento, conforme se observou por meio dos resultados da revisão sistemática realizada nesta pesquisa. Além disso, Fernandes et al. (2017) afirmam que grande parte dos estudos foca nesses temas de forma separada, somente poucos integram as duas perspectivas.

A realização deste trabalho também permitiu constatar que grande parte das pesquisas possui um enfoque quantitativo (principalmente surveys). Sendo assim, outra contribuição diz respeito à análise em profundidade e crítica que o estudo de caso proporciona. Durante a pesquisa também não foram identificados trabalhos que abordaram estudos no setor calçadista, o que também demonstra outra contribuição dessa pesquisa.

No que tange às contribuições gerenciais no contexto das duas empresas, a análise do alinhamento entre a gestão da qualidade da empresa focal e do seu fornecedor de primeira camada forneceu algumas possibilidades de melhorias em ambas as empresas, a fim de otimizar seus processos. Além disso, a empresa focal pode ampliar a confiança entre os membros da cadeia, em especial com o fornecedor de primeira camada foco desse estudo. Tal confiança pode, ao longo do tempo, estreitar o relacionamento entre eles, 
melhorando os processos, a integração e a coordenação da cadeia, de forma a minimizar os custos de transação.

Para dar continuidade à pesquisa sugere-se que sejam desenvolvidos trabalhos que envolvam: a análise da SCQM com um maior número de fornecedores da empresa focal, considerando os principais tipos de matérias-primas fornecidas; o envolvimento de colaboradores de outros setores das empresas focal e fornecedora de forma a apresentar outros pontos de vista acerca do tema pesquisado; a identificação de novas categorias de análise relacionadas ao elo jusante da cadeia; a análise da gestão da qualidade no contexto da cadeia de suprimentos de outros setores produtivos; e, por fim, pesquisas quantitativas (do tipo survey) para verificar a relação entre as categorias de análise identificadas na pesquisa (práticas internas e relação com os fornecedores), por meio de testes de hipóteses. 


\section{REFERÊNCIAS}

CARMIGNAMI, G. Supply chain and quality management: the definition of a standard to implement a process management system in a supply chain. Business Process Management Journal. v. 15, n. 3, p. 395-407, 2009.

DYER, J. H., \& SINGH, H. The relational view: cooperative strategy and sources of interorganizational competitive advantage. Academy of Management Review, v. 23, n. 4, p. 660-679, 1998.

FERNANDES, A. C. et al. Supply chain management and quality management integration: a conceptual model proposal. International Journal of Quality \& Reliability Management, v. 34, n. 1, p. 53-67, 2017.

FOSTER JR. S. T. Towards an understanding of supply chain quality management. Journal of Operations Management. v. 26 , n. 4 , p. $461-467,2008$.

JRAISAT, L. E.; SAWALHA, I. H.; Quality control and supply chain management: a contextual perspective and a case study. Supply Chain Management. v. 18, n. 2, p. 194-207, 2013.

KAYNAK, H.; HARTLEY, J. L. A replication and extension of quality management into the supply chain. Journal of Operations Management. v. 26, n. 4, p. 468-489, 2008.

LIN, C. et al. A structural equation model of supply chain quality management and organizational performance. International Journal of Production Economics. v. 96, n. 3, p. 355-365, 2005.

LIN, C.; KUEI, C. H.; CHAI, K.W. Identifying critical enablers and pathways to high performance supply chain quality management. International Journal of Operations \& Production Management. v. 33, n. 3, p. 347 - 370, 2013.

PALADINI, E. P. Gestão da qualidade: teoria e prática. 2. ed. São Paulo: Atlas, 2004.

PALADINI, E. P. Gestão estratégica da qualidade: princípios, métodos e processos. 2. ed. São Paulo: Atlas, 2009.

PIRES, S. R. I. Gestão da cadeia de suprimentos: conceitos, estratégias, práticas e casos. São Paulo: Atlas, 2004.

ROBINSON, C. J.; MALHOTRA, M. K. Defining the concept of supply chain quality management and its relevance to academic and industrial practice. International Journal of Production Economics. v. 96, n. 3, p. 315-337, 2005.

SLACK, N.; CHAMBERS, S.; JOHNSTON, R. Administração da produção. 2 ed. São Paulo: Atlas, 2002.

SOFYALIOĞLU, Ç. KARTAL B. The selection of global supply chain risk management strategies by using fuzzy analytical hierarchy process: a case from Turkey. Procedia - Social and Behavioral Sciences. v. 58, n. 8, p. 1448-1457, 2012.

STECHEMESSER, K.; GUENTHER, E. Carbon accounting: a systematic literature review. Journal of Cleaner Production, v. 36, n. 1, p.17-38, 2012.

YIN, R. K. Estudo de caso: planejamento e métodos. 3. ed. Porto Alegre: Bookman, 2001.

ZAGHA, R. R. Gestão da qualidade em cadeias de suprimentos do segmento de motores de motores de automóveis. Tese (Doutorado em Engenharia de Produção) - Programa de Pós-Graduação em Engenharia de Produção - PPGEP, Universidade Federal de São Carlos, São Carlos, 2009.

ZENG, J.; PHAN, C. A.; MATSUI, Y. Supply chain quality management practices and performance: an empirical study. Operations Management Research. v. 6, n. 1-2, p. 19-31, 2013

ZHONG, J. et al. Supply chain quality management : an empirical study. International Journal of Contemporary Hospitality Management, v. 28, n. 11, p. 2446-2472, 2016

ZU, X.; KAYNAK, H. An agency theory perspective on supply chain quality management. International Journal of Operations \& Production Management. v. 32, n. 4, p. 423 - 446, 2012. 